\title{
Can inhibition resolve retrieval competition through the control of spreading activation?
}

\author{
JO SAUNDERS \\ University of Wales, Swansea, Wales \\ and \\ MALCOLM D. MACLEOD \\ University of St. Andrews, St. Andrews, Scotland
}

\begin{abstract}
Two experiments are reported in which the mechanisms underlying retrieval-induced forgetting for complex prose materials were investigated, using the independent probe technique pioneered by Anderson and Spellman (1995). These experiments provide additional empirical evidence in support of an inhibitory account of memory. Specifically, evidence emerged not only for the inhibition of nonpracticed items from practiced sets (i.e., first-order effects), but also for the inhibition of items from nonpracticed sets that were semantically related to practiced items in practiced sets (i.e., crosscategory effects) and for items from nonpracticed sets that were semantically related to nonpracticed items in practiced sets (i.e., second-order effects). These findings are considered in terms of Anderson and Spellman's model of inhibitory processing. We also outline an alternative inhibitory interpretation. Specifically, we consider how inhibition may function as a way of controlling the spread of activation and what implications this may have for the flexibility and adaptiveness of memory.
\end{abstract}

Memory allows us to function effectively in a social world that is both complex and subject to continuous change. Without the ability to remember who we are, what we have done, and what we intend to do, we would cease to function in any meaningful way. Perhaps because of this pivotal role, we become aware of the importance of memory only when it fails to capture the information we require. The recall of a friend's new address, a mobile phone number, or even the name of one's current partner are typical of the everyday retrieval tasks that can be frustrated by unwanted competition from related memories. If only there were some way of setting aside unwanted related memories, we might be better placed to retrieve the information we wish to remember. Of course, for the most part, this is exactly what we appear to do. But how does memory accomplish this conjuring feat, given the vast array of interrelated memories accumulated over a lifetime? What kind of mechanism is responsible for resolving retrieval competition between related memories?

In contrast to more traditional views of memory, in which forgetting tends to be characterized as inconvenient lapses in memorial ability, recent theorizing suggests that some forms of forgetting may possess an adaptive func-

This research was supported by an Economic and Social Research Council Fellowship to the first author and a British Academy Readership to the second author. We also thank Mike Anderson, Doug Nelson, and Sean Polyn for their helpful comments on an earlier version of the manuscript. Correspondence concerning this article should be addressed to M. D. MacLeod, Social and Applied Cognition Lab, School of Psychology, University of St. Andrews, St. Mary's College, South Street, St. Andrews, Fife KY16 9JP, Scotland (e-mail: mdm@st-and.ac.uk). tion - that is, the resolution of retrieval competition (Anderson \& Bjork, 1994; R. A. Bjork, 1989). Specifically, it has been argued that the retrieval of desired memories can be promoted by the active forgetting or inhibition of related memories (Anderson, R. A. Bjork, \& E. L. Bjork, 1994; Anderson \& Spellman, 1995). Support for this view draws upon an extensive literature concerned with directed (E. L. Bjork, Bjork, \& Anderson, 1998; R. A. Bjork, 1989) and nondirected (Anderson, 2003; M. D. MacLeod, Bjork, \& Bjork, 2003) forgetting. The present article contributes to this debate and clarifies some of the unresolved issues by providing an in-depth exploration of the mechanisms responsible for retrieval-induced forgetting in the retrieval practice paradigm (see also Anderson, 2003; Levy \& Anderson, 2002).

The retrieval practice paradigm typically comprises four phases: a study phase, a retrieval practice phase, a distractor, and a final recall task. In the study phase, participants are presented with lists of categories containing related exemplars (e.g., fruit-apple, fruit-orange, drink-beer, drink-wine). Following this initial stage, the participants are presented with a cued retrieval practice task in which a subset of exemplars about some of the categories are repeatedly retrieved (e.g., fruit-ap___, fruit-or____ $)$. This procedure has the effect of creating three distinct item types: practiced exemplars from the practiced category (i.e., $\mathrm{Rp}+$ items), unpracticed exemplars from the practiced category (i.e., Rp- items), and unpracticed exemplars from the unpracticed category (i.e., Nrp items).

During the final recall task, in which the participants are encouraged to recall all the items presented originally, practiced $\mathrm{Rp}+$ items tend to be better recalled than un- 
practiced Nrp items. This facilitation effect is expected, given that retrieval represents a potent learning event (Allen, Mahler, \& Estes, 1969; Carrier \& Pashler, 1992). What is surprising, however, is that rather than improving recall performance for the remaining unpracticed category members, as is predicted by both facilitatory priming (e.g., Neely, 1976, 1977) and spreading activation (Freedman \& Loftus, 1971; Loftus, 1973; Roediger $\&$ McDermott, 1995) models, guided retrieval practice typically results in poorer recall, as compared with Nrp baseline performance.

Anderson and colleagues (Anderson, 2003; Anderson \& R. A. Bjork, 1994; Anderson et al., 1994; Anderson \& Spellman, 1995) have argued that this pattern of retrievalinduced forgetting is consistent with an inhibitory account of memory, whereby related competing memories are actively inhibited in such a way that retrieval competition is resolved. Anderson and Spellman, however, pointed out that this pattern of recall performance does not in itself provide unequivocal evidence of an inhibitory mechanism. Rather, noninhibitory mechanisms, such as associative interference, may be just as valid. Specifically, retrieval-induced forgetting may be due to interference occurring along the retrieval route between the cue and a particular exemplar (Anderson \& Bjork, 1994; Anderson $\&$ Neely, 1996). Since multiple memories tend to be associated with a single cue, any increase in the number of items accessed by a particular cue is likely to lead to a corresponding increase in competition. Thus, as Anderson and Spellman argued, if noninhibitory mechanisms are responsible for the kind of forgetting typically observed in the retrieval practice paradigm, it should be cue specific. In other words, retrieval-induced forgetting should emerge only when the retrieval cue employed at study and retrieval practice is also employed at final test; that is, retrieval-induced forgetting should fail to emerge where novel cues are employed at final test (see Figure 1 for an example of cue-dependent forgetting).

An inhibitory account of retrieval-induced forgetting, in contrast, predicts that this pattern of forgetting is cue independent. In other words, retrieval-induced forgetting will emerge even when novel cues (or independent cues; Anderson \& Spellman, 1995) are employed during final test. Anderson and Spellman argued that the reason for this lies in the inhibition of the exemplar itself. Thus, even where independent cues are employed, $\mathrm{Rp}$ - items should remain unavailable to conscious inspection and, therefore, be more poorly recalled than are Nrp items (see also Anderson \& Bell, 2001; Anderson, Green, \& McCulloch, 2000; Johnson \& Anderson, 2004; Shivde \& Anderson, 2001; see Figure 2 for an example of cue-independent forgetting).

In developing this line of argument still further, Anderson and Spellman (1995) considered some of the potential ramifications of an inhibitory account for the recall of items in nontarget categories (i.e., nonpracticed categories). Specifically, they argued that items from the unpracticed category that are semantically related to members of the practiced category possess the potential to interfere with the retrieval of practiced items by virtue of sharing the same retrieval cue. In other words, retrieval competition is driven by a shared retrieval cue. Thus, trying to retrieve the item blood using the cue red can impair other items explicitly studied under that cue (e.g., red-tomato) or other items explicitly linked to that cue on the basis of prior knowledge (e.g., food-cherry) to the extent that such items are activated by their shared cue during retrieval practice (i.e., red). Consequently, such items become subject to the same inhibitory forces that affect the retrieval of Rp-items (see Figure 3). This cross-category impair-

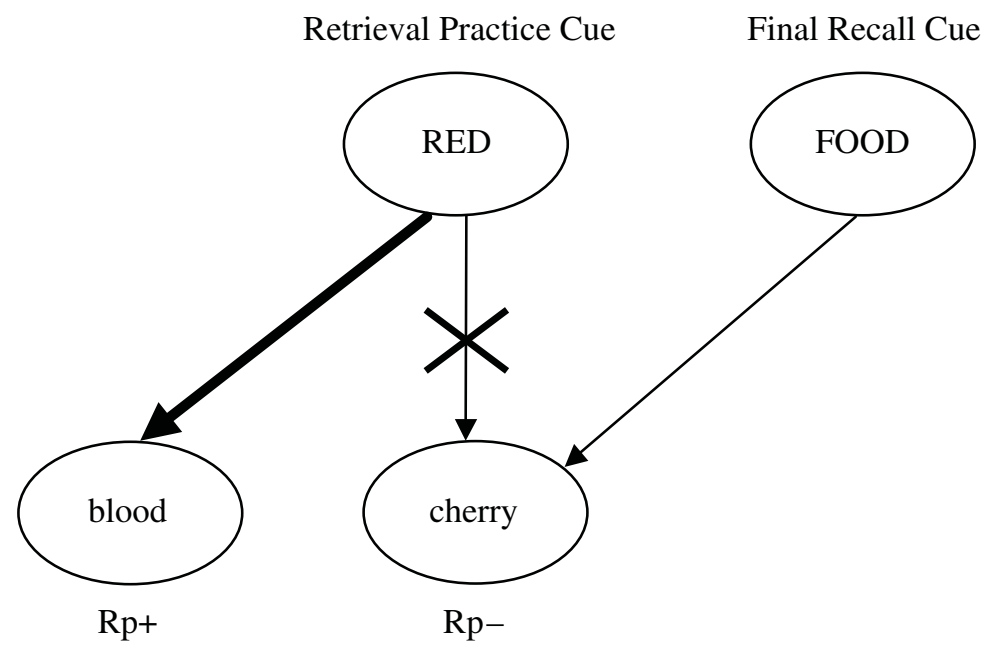

Figure 1. Retrieval-induced forgetting as a cue-dependent forgetting effect. Noninhibitory theories assume that retrieval-induced forgetting is due to interference occurring along the retrieval route between the $R p-$ item cherry and the retrieval practice cue red. The $\mathrm{Rp}-$ item can, however, be retrieved if a new retrieval route is used that is free from interference, such as food. 


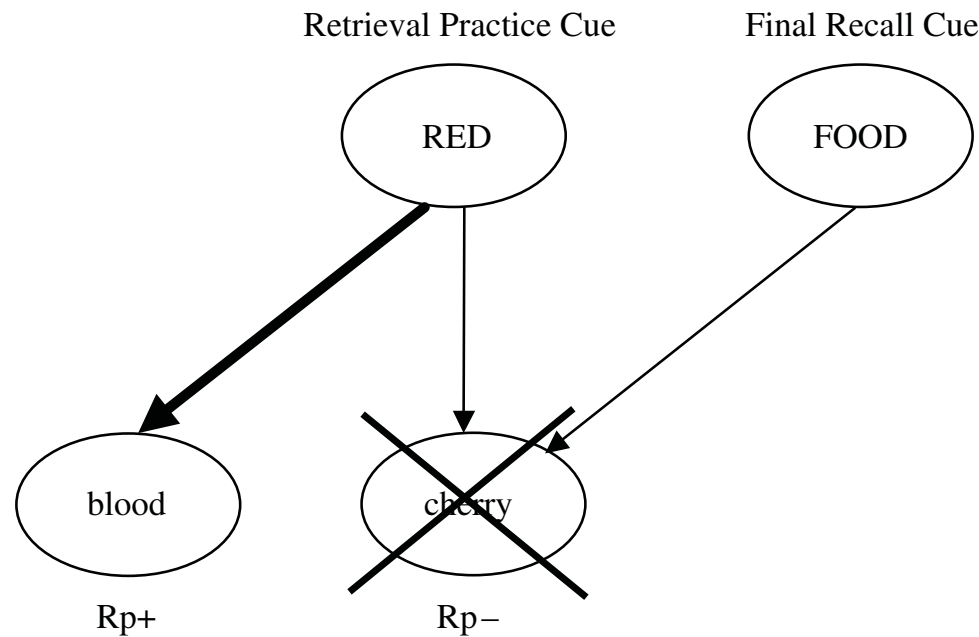

Figure 2. Retrieval-induced forgetting as a cue-independent forgetting effect. Inhibitory theories assume that retrieval-induced forgetting is due to the specific inhibition of the memorial representation of the $R p-$ item, rather than to interference occurring earlier in the retrieval processes. Thus, cherry should remain inhibited even when a novel retrieval cue is employed.

ment of related Nrp items occurs because these items effectively constitute the equivalent of a second $\mathrm{Rp}-$ set. The retrieval of unrelated Nrp items should, by contrast, remain unimpaired (see Anderson \& Spellman, 1995, Experiment 1).

In a further extension to this argument, Anderson and Spellman (1995, Experiments 2 and 4) indicated that even Nrp items that are not directly associated with $\mathrm{Rp}+$ items but are semantically linked to $\mathrm{Rp}-$ items (i.e., linked to items that are in direct competition for retrieval with $\mathrm{Rp}+$ items) may also be subject to inhibitory processing (see
Figure 4). Anderson and Spellman were careful to consider how such a pattern of forgetting could be accounted for by noninhibitory means. In particular, they considered the possibility that the production of such effects may be dependent on more items being associated with a particular cue than in relevant control conditions in which $\mathrm{Rp}-$ items do not share related categories with any Nrp items. Thus, it could be argued that any decrement in Nrprelated item performance may simply be due to cue overload (Watkins, 1975, 1978), rather than to inhibitory processing. In exploring this possibility, Anderson and Spellman dem-

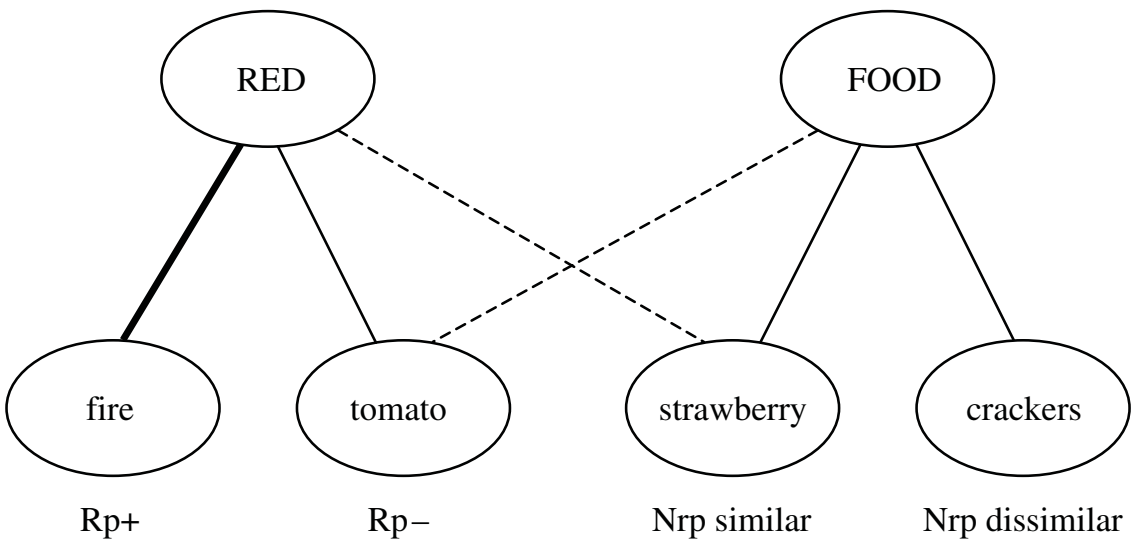

Figure 3. Cross-category inhibition, which refers to the impaired recall of Nrp items that are also semantic members of the practiced category. If inhibitory processes are responsible for retrieval-induced forgetting (i.e., depressed recall performance for Rp- items), this inhibitory effect should also "cross" to items of another category that contains items that are semantically associated with the items in the practiced category. $R p+$, practiced item from the practiced category; Rp-, unpracticed item from the practiced category; Nrp similar, item from the unpracticed category that is semantically related to the practiced category; Nrp dissimilar, item from the unpracticed category that is semantically unrelated to the item in the practiced category. 


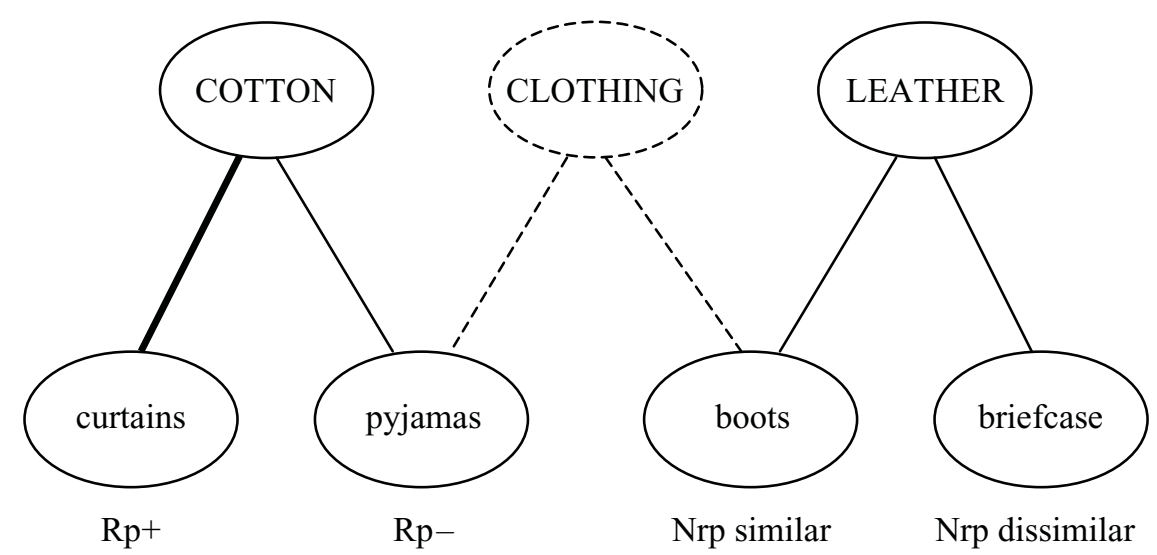

Figure 4. Second-order inhibition. Items from the unpracticed category that share no semantic similarity with the practiced item may still be susceptible to second-order inhibition. While leather-boots is semantically dissimilar to the $\mathrm{Rp}+$ item cotton-curtains, it is semantically similar to the inhibited Rp-item cotton-pyjamas and may, therefore, also be susceptible to inhibition. The unrelated Nrp item, however, should remain unaffected by inhibition, due to its semantic dissimilarity to items within the practiced category. $R p+$, practiced item from the practiced category; $\mathrm{Rp}-$, unpracticed item from the practiced category; Nrp similar, item from the unpracticed category that is semantically related to the item in the practiced category; Nrp dissimilar, item from the unpracticed category that is semantically unrelated to the item in the practiced category.

onstrated that second-order effects (i.e., depressed recall of Nrp items that are related to Rp-items) emerged only when participants performed retrieval practice on target items. They argued that, if cue overload had been responsible, a decrement in related Nrp items would have been evident even under conditions in which no relevant retrieval practice had taken place.

Despite the cogency of these arguments and the empirical support that has been amassed by Anderson and colleagues for such an inhibitory account (for reviews, see Anderson, 2003; Levy \& Anderson, 2002), some researchers have begun to express doubts about the extent to which inhibitory processes are actually involved in memory. Sahakyan and Kelley (2002), for example, have recently questioned the retrieval inhibition account of directed forgetting and have, instead, proposed that contextual change may be responsible for the performance effects associated with an instruction to forget on final recall. Specifically, Sahakyan and Kelley proposed that the forget instruction in the directed-forgetting paradigm elicits a change in the internal mental context between the to-be-forgotten and to-be-remembered lists. For example, if participants are encouraged to think of something other than the experiment, such an instruction may be sufficient to induce a strong change of internal context between lists. The participants engaged in such a task would, therefore, be more likely to treat both lists as separate events. If the contextual cues provided at test do not match the cues encoded during the study phase, the participants are likely to recall those items more poorly. Conversely, if the lists are encoded as separate events, proactive interference effects should be reduced.

Similarly, C. M. MacLeod, Dodd, Sheard, Wilson, and Bibi (2003) have argued that the strategy disruption ac- count of part-set cuing may provide a more appropriate explanation of retrieval-induced forgetting. Strategy disruption suggests that presenting items as cues disrupts the natural recall order of items by forcing participants to engage in a serial recall order that is incompatible with the original organization of the categories and their exemplars (Basden \& Basden, 1995; Basden, Basden, \& Galloway, 1977). In terms of the retrieval practice paradigm, the strategy disruption account suggests that selective retrieval of $\mathrm{Rp}+$ items disrupts the original organization of items within categories. As a result, it becomes much harder to recall the nonpracticed $\mathrm{Rp}-$ items successfully. In contrast, since none of the Nrp items has been practiced, the Nrp items remain relatively easy to recall (i.e., no strategy disruption occurs in nonpracticed categories). C. M. MacLeod and colleagues suggested that various findings from the retrieval-induced forgetting literature may support the disrupted strategy account over an inhibitory one. It could be argued, for example, that the dissipation of retrieval-induced forgetting over time (M. D. MacLeod \& Macrae, 2001) may actually be due to the reinstatement of the original organization of categories, rather than to the presence of inhibitory processes. Similarly, it could be argued that integration (Anderson \& McCulloch, 1999) and distinctive processing (Macrae \& Roseveare, 2002; Smith $\&$ Hunt, 2000) may serve to protect categories from the deleterious effects of disrupted retrieval, rather than from the effects of inhibitory processing.

Although disrupted retrieval can account for some of the findings within the retrieval-induced forgetting literature, it would be premature at this stage to dismiss the inhibitory account as propounded by Anderson and colleagues. Disrupted retrieval, for example, cannot readily explain cross-category or second-order effects. As has al- 
ready been stated, the disrupted retrieval account assumes that retrieval practice disrupts only the final recall of $\mathrm{Rp}-$ items. Since none of the items from the unpracticed category undergo retrieval practice, the recall of Nrp items related to the practiced category should be unaffected. Clearly, since Nrp items that are related to the practiced category can be impaired by retrieval practice (i.e., the production of second-order and cross-category effects), a process other than disrupted retrieval is likely to be responsible. In light of this continuing debate, it would seem timely to reconsider the empirical evidence for the three major tenets on which Anderson and Spellman's (1995) inhibitory account of forgetting is based-that is, cueindependent forgetting, cross-category inhibition, and second-order inhibition.

Unfortunately, to date, much of the published empirical work that supports these tenets has come from Anderson's own laboratories. The principal reason for this is that the construction of appropriate experimental materials is both time consuming and complex and, to be blunt, discourages many researchers from exploring these interesting ideas. Materials have to be strenuously piloted before the main experiments can even be run, in order to determine their semantic relatedness and the appropriateness of retrieval cues. These difficulties, however, are not insurmountable, and indeed, if we wish to determine the extent to which inhibitory processes play a part in everyday memory, further studies need to be performed in which more varied stimulus materials are used. Nevertheless, these strictures cast doubt on the extent to which such inhibitory processes apply beyond the category-exemplar pairs typically employed by Anderson and colleagues.

Given the current level of interest in inhibitory accounts of memory, the present article sets out to establish whether the three major platforms on which Anderson and Spellman's (1995) inhibitory account are based are limited to memory for category-exemplar pairs. Using experimental materials different from those typically employed by Anderson and colleagues, we set out in our first experiment to consider the evidence for cue-independent forgetting. In our second experiment, we explored cross-category impairment and second-order effects. We will highlight some of the technical aspects involved in establishing such effects, consider further the processes involved in resolving unwanted competition at retrieval from related memories, and evaluate the evidence for an inhibitory account of memory.

\section{EXPERIMENT 1}

Using the criteria and the independent cue technique employed by Anderson and Spellman (1995), we set out to establish that the observed decrease in Rp- item performance in the retrieval practice paradigm is due to inhibition of the exemplar, rather than to interference specific to cue-exemplar links. On the basis of Anderson and Spellman's logic, the outcomes of our experiment should be clear. If retrieval-induced forgetting is governed primarily by the actions of noninhibitory processes, the use of novel cues at final test should be sufficient to reinstate $\mathrm{Rp}-$ item performance; that is, there will be no depression in $\mathrm{Rp}$ - item performance, relative to the Nrp baseline. If, on the other hand, $\mathrm{Rp}-$ item performance remains depressed despite the use of novel cues at test, we can infer that the exemplar itself has been inhibited, since the novel cues at test should have proved sufficient to circumvent any interference caused to specific cue-exemplar links.

\section{Method}

Participants and Design. Fifty students attending the University of St. Andrews (32 men and 18 women) participated on a voluntary basis in this experiment. The experiment had an incomplete factorial design, whereby there was a single between-subjects factor (retrieval practice: relevant practice or no relevant practice) and a single within-subjects factor (item type: $\mathrm{Rp}+, \mathrm{Rp}-$, or Nrp) for the relevant practice condition only. Inasmuch as relevant retrieval practice is required to produce different item types, no such differentiation was possible in the control condition, since no relevant retrieval practice had taken place. Rather, overall item performance in the control condition served as a between-subjects baseline against which item performance in the relevant retrieval practice condition could be compared. Each condition contained 25 participants.

Study materials. In the study phase, the participants were required to read two narratives containing information about two separate burglaries (see Appendix A). The first part of each narrative contained scene-setting information about when and where the incidents occurred. One narrative concerned the theft of 10 items from the Thompson's house while the family was on vacation. The second narrative concerned the theft of 10 items from the Williams's house while the family was visiting relatives. Each item was presented embedded within a sentence describing from where in the house each item had been stolen (e.g., "The mobile phone had been in the hallway. It had belonged to Mr. Thompson who needed it for his job as a doctor"). The participants were informed that the underlined words represented the stolen items. Each item was presented on a separate page of a booklet. Items for each burglary were presented in block format (i.e., the presentation of the narrative and all items from the Thompson's house was followed by the narrative and all the items from the Williams's house, or vice versa). Presentation of target items was randomized within each block (see Saunders \& MacLeod, 2002), and presentation order of the two narratives was counterbalanced. Information sets for each house consisted of two subgroups, each containing 5 items. This allowed for the creation of a practiced set (i.e., Rp+ group) and an unpracticed set (i.e., $\mathrm{Rp}-$ group) for each house. Items were chosen in such a way that only weak semantic associations existed between one group of items and another.

The degree of semantic relatedness was established in earlier pilot work in which an independent group of participants $(n=10)$ had been presented with a list of 83 common household items. The participants were asked to group items by their perceived similarity and, on completion of this task, to state the basis for these groupings. For example, the participants might choose to group items such as a microwave, a fridge, and a cooker together as examples of electrical goods or as items that one might find in a kitchen. Since we were interested in how the participants would perceive associations between items, we gave no guidance on how the groupings should be constituted or the number of groupings that could be generated from the 83 items.

On the basis of these groupings, we then calculated the relatedness of each item with each other item. Thus, for a grouping that consisted of four items, a similarity rating was calculated for each of the six possible pairings. We did this by assigning a score of .1 to each pairing made by each participant. Thus, if only 1 participant had paired guitar and jeans together, the pairing was given a score of .1. In contrast, if 7 participants had paired guitar with jeans, the pairing was given a score of .7. The relatedness of each subset was established by comparing each item in each subset with each item in 
all the other subsets. Once a value had been assigned to each possible pairing, the total value of all the possible pairings for the two subsets being compared was divided by the total number of actual pairings made for those items from the two subsets. This allowed us to produce a mean similarity rating for each subset comparison, where 0 indicated no perceived similarity and 1 indicated that they were very similar. Mean similarity for each subset was calculated: Thompson's Subset $1=.01$; Thompson's Subset $2=.016$; Williams's Subset $1=.008$; Williams's Subset $2=.01$.

We also chose items that differed from every other target item in respect of their first two letters (Thompson's house, hockey stick, mobile phone, PlayStation, necklace, guitar, armchair, painting, microwave, lamp, and vase; Williams's house, perfume, rucksack, hammer, fountain pen, telescope, clock, stereo, leather jacket, printer, and calculator). This ensured that when a stem completion type task was used during the independent cuing phase of the study, each item could be prompted by a unique two-letter stem. Similar materials had previously been shown to produce retrieval-induced forgetting in other studies (e.g., Saunders \& MacLeod, 2002, 2004). The labels generated by the participants to describe their groupings also provided the basis for the independent cues employed in the last phase of the retrieval practice paradigm.

Retrieval practice questions. The participants in the experimental condition received three sets of questions about half of the items from one of the houses (i.e., 15 retrieval cues in total, relating to five of the stolen items from one of the houses). The difficulty of each set of questions increased as the participants progressed through the retrieval practice booklet. This procedure was based on earlier work by Landauer and Bjork (1978), which showed that practice effects can be maximized by progressively increasing the difficulty of the retrieval task. For example, in order to retrieve the item telescope, the participants were initially prompted with "This item was in the Williams's House, and is an instrument used in astronomy" and finally were prompted with "This item was in the Williams's House, and is a cylindrical device that uses a combination of lenses and/or curved mirrors." Pilot work had established the difficulty of the prompts employed in the retrieval practice booklet (see M. D. MacLeod, 2002; Saunders \& MacLeod, 2002). The participants in the control condition, in contrast, did not perform retrieval practice on any of the stolen items from either house. Rather, they completed a nonrelevant retrieval practice task (see Macrae \& MacLeod, 1999), in which they were required to retrieve the names of capital cities of the world (e.g., "The capital city of Cuba is Ha___ "; "The capital city of Australia is $\mathrm{Ca} \_$_). In this way, we could ensure that the participants in the control condition were engaged in the same kind of activity (i.e., the retrieval of information from memory) as were the participants in the retrieval practice condition but that, in the case of the controls, this retrieval activity had no bearing on any of the items presented in the initial phase of the experiment.

Recall booklets. In the present experiment, a cued-recall task based on Anderson and Spellman's (1995) independent cue technique was employed (see Appendix B). The independent cue task was presented in a four-page booklet that contained novel cues (i.e., retrieval cues that had not been used during the study or retrieval practice phases) plus a two-letter stem unique to that item (e.g., $m u$ sical instrument-gu___ ). The appropriateness of the cues had also been established in previous pilot work. Output order was controlled by cuing the retrieval of $\mathrm{Rp}$ - items before the retrieval of $\mathrm{Rp}+$ items, in order to minimize output interference (i.e., where the early output of practiced items has the potential to interfere with the subsequent output of weaker, unpracticed items). Specifically, the cuing of Rp- items was interspersed with the cuing of Nrp items during the first half of the recall booklet, and the remaining Nrp items were interspersed with the cuing of the $\mathrm{Rp}+$ items. Thus, the order of items cued in the recall booklet was $\mathrm{Rp}-, \mathrm{Nrp}, \mathrm{Rp}-, \mathrm{Nrp} \ldots \mathrm{Rp}+$, Nrp, Rp+, etc.).
Procedure. The participants arrived at the laboratory in groups of up to 5 , were greeted by a female experimenter, and were randomly assigned to either the experimental (i.e., relevant retrieval practice) or the control (i.e., nonrelevant retrieval practice) condition. The experiment proceeded in a manner similar to that previously described by Shaw, Bjork, and Handal (1995) and M. D. MacLeod (2002), whereby each participant completed a study phase, a retrieval practice phase interleaved with distractor tasks, and a final recall task. The participants were informed that they would be taking part in a memory experiment and were instructed to read two narratives about two separate burglaries that were contained within a study booklet.

One narrative concerned a burglary at the Thompson's family home. The first part of the narrative contained scene-setting information, which described how the family returned home following their summer vacation to discover that their house had been burglarized in their absence. The participants were given $45 \mathrm{sec}$ to study this information before proceeding to the target items. Each item was presented on a separate page of the study booklet for $5 \mathrm{sec}$ before the participants were prompted to proceed to the next item. Having studied both the scene-setting information and the target items, the participants were instructed to read a second narrative concerning the Williams's house, which detailed the arrival home of the Williams family on New Year's Eve to discover that a number of items had been stolen from their house. The order of presentation of the narratives was counterbalanced throughout.

On completion of the study phase, the participants proceeded to the retrieval practice task. In agreement with other retrieval practice tasks (e.g., M. D. MacLeod, 2002; M. D. MacLeod \& Macrae, 2001; Macrae \& MacLeod, 1999), target items from one house formed the practiced category, consisting of $\mathrm{Rp}+$ and $\mathrm{Rp}-$ items, whereas items from the remaining house formed the unpracticed category (i.e., Nrp items). Target items from the Thompson's and the Williams's houses appeared equally as often in the practiced and the unpracticed categories and were fully counterbalanced. The presentation order of items in each subset was also fully randomized for each participant.

During the retrieval practice task, the participants were prompted to retrieve half of the items from the practiced category (i.e., five $\mathrm{Rp}+$ items) by completing a series of questions that cued each item. Each $\mathrm{Rp}+$ item was practiced three times. Each retrieval practice task was interleaved with distractors that increased in length after each practiced set (i.e., the first retrieval practice task was followed by a 3-min distractor task, the second retrieval practice task was followed by a 4-min distractor task, and the final retrieval practice task was followed by a 5 -min distractor task). Distractor tasks consisted of pages of anagrams (i.e., fruit, vegetables, and academic subjects). No participant completed the tasks in the allocated time. The participants in the control condition followed the same procedure, with the exception that they completed a nonrelevant retrieval practice task (see Macrae \& MacLeod, 1999; Saunders \& MacLeod, 2002), in which they were required to retrieve the names of capital cities of the world.

On completing the third and final distractor task, the participants were required to complete an independent cued-recall task (see Anderson \& Spellman, 1995) that was contained within a four-page booklet. Five items were cued on each page of the booklet, and the participants were allocated $10 \mathrm{sec}$ to complete each stem before being prompted to complete the next cued word stem. On completion of this task, the participants were thanked for their participation, debriefed, and dismissed.

\section{Results and Discussion}

The retrieval practice success rate for the relevant retrieval practice condition was $85 \%$. The recall scores (proportion correct) within each condition were transformed 
using an arcsin transformation, in order to establish homogeneity of variance (see Snedecor \& Cochran, 1980, pp. 290-291). A single factor (item type: $\mathrm{Rp}+, \mathrm{Rp}-$, or Nrp) within-subjects ANOVA demonstrated a significant main effect of item type for the relevant retrieval practice condition $\left[F(2,48)=22.70, M S_{\mathrm{e}}=0.08, p<.01\right]$. Cohen's $f$ was calculated as an unbiased measure of effect size (Cohen, 1988). This indicated the presence of a large effect (Cohen's $f=.56$ ). Using Holm's sequential Bonferroni approach, pairwise comparisons confirmed the presence of both facilitatory effects [i.e., Rp $+>\mathrm{Nrp}$, $M \mathrm{~s}=.90$ vs. .76 , respectively; $t(24)=4.37, p<.01]$ and retrieval-induced forgetting effects [i.e., Rp $-<\mathrm{Nrp}$, $M \mathrm{~s}=.63$ vs. .76, respectively; $t(24)=-2.09, p<.05]$.

According to Anderson and Spellman's (1995) criteria, the independent cue technique provides a method for determining whether retrieval-induced forgetting is primarily the result of inhibitory or noninhibitory processes. Thus, the fact that retrieval-induced forgetting emerged even when independent cues were employed provides strong inference that inhibitory processes had been active. In this experiment, we can also be confident that the decrement in $\mathrm{Rp}-$ performance was a real one, given that there was no difference in Nrp recall performance between relevant $(M=.76)$ and nonrelevant $(M=.78)$ retrieval practice conditions $[F(1,48)=0.08$, n.s. $]$. In other words, the retrieval-induced forgetting observed was due to a genuine reduction in $\mathrm{Rp}$ - item recall performance, rather than to any enhancement in Nrp baseline performance.

It is also apparent from this experiment that cueindependent forgetting effects do not need to rely upon the use of preexisting taxonomic categories. Specifically, we demonstrated that such effects can extend to categoryexemplar pairings (i.e., a particular house and item) that are episodically determined. It is conceivable, therefore, that this kind of forgetting may extend beyond the confines of highly controlled laboratory experiments to real-life situations, such as employment interviews, eyewitnessing, and interpersonal relationships (see E. L. Bjork, R. A. Bjork \& MacLeod, 2006, for a discussion). Indeed, the difference in recall performance between $\mathrm{Rp}-$ and Nrp items in the present study was -.13 , which is comparable in magnitude to the level of impairment found in other retrieval-induced forgetting experiments in which novel cues had not been provided at test (see, e.g., Anderson et al., 1994; M. D. MacLeod, 2002; M. D. MacLeod \& Macrae, 2001; Macrae $\&$ MacLeod, 1999). See Table 1 for a summary of the mean recall performance for each item type in the relevant and nonrelevant retrieval practice conditions.

\section{EXPERIMENT 2}

Having established that cue-independent forgetting is replicable, we turn to investigate the extent to which second-order and cross-category effects can be produced when novel cues are employed at test. We believe it is important to establish these effects, given that there is potential confusion regarding the interpretation of the crosscategory effect as originally reported by Anderson and
Table 1

Mean Recall Performance (With Standard Deviations) for Retrieval Practice and Control (Nonrelevant Practice) Conditions in Experiment 1

\begin{tabular}{|c|c|c|c|c|}
\hline \multirow[b]{2}{*}{ Condition } & \multicolumn{3}{|c|}{ Item Type } & \multirow{2}{*}{$\begin{array}{c}\text { Retrieval-Induced } \\
\text { Forgetting } \\
{[(\mathrm{Rp}-)-\mathrm{Nrp}]}\end{array}$} \\
\hline & $\mathrm{Rp}+$ & $\mathrm{Rp}-$ & Nrp & \\
\hline Retrieval practice & $\begin{array}{c}.90 \\
(.10)\end{array}$ & $\begin{array}{c}.63 \\
(.23)\end{array}$ & $\begin{array}{c}.76 \\
(.13)\end{array}$ & -.13 \\
\hline
\end{tabular}

Note-Rp+, practiced items from the practiced category; Rp-, unpracticed items from the practiced category; Nrp, unpracticed items from the unpracticed category. Recall of items in the control condition $=.78$ $(S D=.09)$.

Spellman (1995, Experiment 1). Specifically, it remains unclear whether the decrement in Nrp item performance reported by Anderson and Spellman was due to the semantic relatedness of Nrp items to $\mathrm{Rp}+$ or to their relatedness to $\mathrm{Rp}-$ items.

Given that the driving force underlying such effects is considered to be the resolution of retrieval competition (Anderson et al., 1994; Anderson \& Neely, 1996), the greatest threat to the successful retrieval of Rp+ items should come from either Rp - items or any Nrp items that are semantically related to $\mathrm{Rp}+$ items (or more specifically, those that are likely to share the same retrieval cue). In our second experiment, therefore, we set out to establish the following: (1) If there are subcategories of related items that span both incidents, can the practice status of some of those items influence the recall of semantically related items in the unpracticed incident? (2) If unpracticed items from the unpracticed incident are similar to Rp + items, is this sufficient to produce cross-category impairment, or will they benefit from the prior retrieval of related information? (3) If some items from the unpracticed category are similar to Rp - items, will these Nrp-similar items also show impairment (i.e., second-order inhibition)?

In order to accomplish this, we modified the experimental materials so as to produce the necessary subcategories of related items that spanned both incidents. This required the Nrp category to be subdivided into two distinct item types: Nrp-similar items and Nrp-dissimilar items. Nrp-similar items were items from the unpracticed category that were semantically similar to exemplars from the practiced category. Thus, Nrp items were identified as having semantic associations with either $\mathrm{Rp}+$ items (i.e., Nrp similar to Rp + items; see Figure 5) or Rp - items (i.e., Nrp similar to Rp - items; see Figure 6). Nrp-dissimilar items, in contrast, were semantically unrelated to any of the items in the practiced set. The independent cue method employed in our first experiment was also employed throughout the final recall task in this experiment, in order to determine whether inhibitory processes underlie the predicted decrements in recall performance (see Anderson \& Spellman, 1995).

\section{Method}

Participants and Design. Ninety students from the University of St. Andrews (52 men and 38 women) participated on a voluntary basis in this experiment. The experiment had an incomplete factorial 


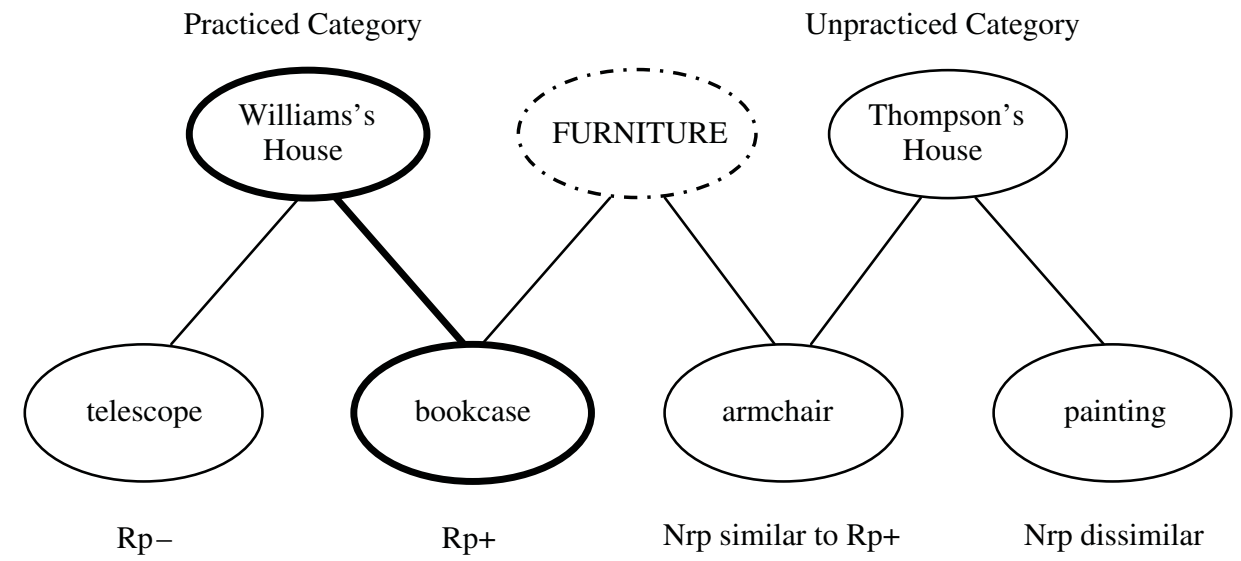

Figure 5. An example of cross-category inhibition of Nrp similar to Rp+ items. The Nrp similar to $R p+$ item Thompson's house-armchair shares the implicit semantic category furniture with the $\mathrm{Rp}+$ item Williams's house-bookcase. Thus, armchair is in direct competition for retrieval with the practiced item bookcase. As a result, armchair is vulnerable to inhibition, in order to prevent it from interfering with the retrieval of the $\mathrm{Rp}+$ item. $\mathrm{Rp}+$, practiced item from the practiced category; $\mathrm{Rp}-$, unpracticed item from the practiced category; Nrp similar to Rp+, item from the unpracticed category that is semantically similar to the $R p+$ item; Nrp dissimilar, item from the unpracticed category that is semantically dissimilar to all items from the practiced category.

design, whereby there was a single between-subjects factor (retrieval practice: relevant or nonrelevant) and a single within-subjects factor (item type: $\mathrm{Rp}+, \mathrm{Rp}-$, Nrp similar to $\mathrm{Rp}+$, Nrp similar to $\mathrm{Rp}-$, or Nrp dissimilar) for the relevant practice manipulation only. However, in this experiment, there was the added complication that we wished to explore the effect of selected retrieval practice on Nrp items related to $\mathrm{Rp}+$ items (i.e., cross-category effects) and on Nrp items related to $\mathrm{Rp}-$ items (i.e., second-order effects), relative to Nrp items that were unrelated to both $\mathrm{Rp}+$ and $\mathrm{Rp}-$ items. In order to accomplish this, we nested the relatedness of Nrp items to practice set items within the relevant practice manipulation. This gave rise to three conditions: a relevant practice condition in which a subset of Nrp items were related to Rp+ items (but not to $\mathrm{Rp}-$ items), which we have called the $\mathrm{Nrp}$ related to $\mathrm{Rp}+$ condition; a relevant practice condition in which a subset of Nrp items were related to $\mathrm{Rp}-$ items (but not to $\mathrm{Rp}+$ items), which we have called the $\mathrm{Nrp}$ related to $\mathrm{Rp}$ - condition; and a control condition in which no relevant retrieval practice had occurred. This design produced the following measures of recall performance: $\mathrm{Rp}+, \mathrm{Rp}-$, and $\mathrm{Nrp}-$ dissimilar item performance for both relevant practice conditions; Nrp similar to Rp + item performance for the Nrp related to Rp+ condition only; and Nrp similar to Rp- item performance for the

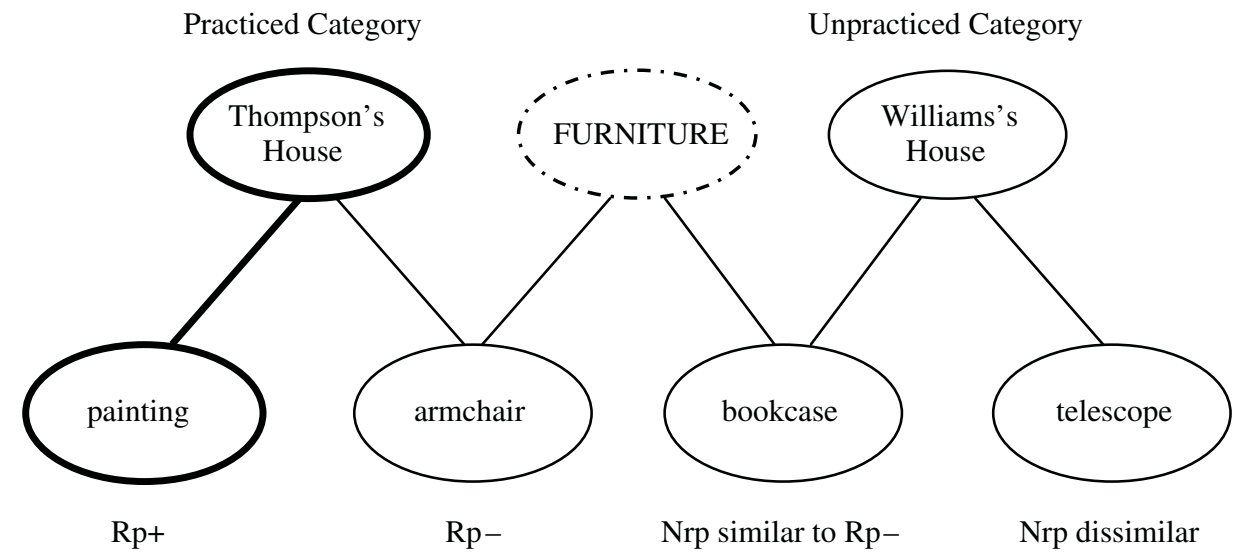

Figure 6. An example of second-order inhibition of Nrp similar to Rp- items. Although the Nrp similar to Rp- item Williams's house-bookcase does not share any direct semantic similarity with the Rp+ item Thompson's house-painting and, therefore, does not compete with it for retrieval, it does share the implicit semantic category furniture with the Rp-item Thompson's house-armchair. Since armchair is inhibited, due to its competition for retrieval with the practiced item, the Nrp similar to $\mathbf{R p}-$ item is also vulnerable to inhibition. $\mathrm{Rp}+$, practiced item from the practiced category; $\mathrm{Rp}-$, unpracticed item from the practiced category; Nrp similar to Rp-, item from the unpracticed category that is semantically similar to the Rp- item; Nrp dissimilar, item from the unpracticed category that is semantically dissimilar to all items from the practiced category. 
Nrp related to $\mathrm{Rp}$ - condition only. The control condition served as a between-subjects baseline against which Nrp performance in the relevant practice conditions could be compared. Thirty participants were randomly assigned to each condition.

Materials. The general format of the materials was maintained from the previous experiment, with the exception that 12 items were stolen from each house (see Appendix C). As in the previous experiment, one house formed the practice category, and the remaining house formed the unpracticed category (counterbalanced throughout). Items within each practiced category were divided into practiced $(\mathrm{Rp}+)$ or unpracticed $(\mathrm{Rp}-)$ items. Similarly, the unpracticed category was divided into items that were semantically related to items from the practiced category (either Nrp similar to Rp+ items or Nrp similar to Rp - items) or items that were semantically dissimilar to all the items from the practiced category (Nrp-dissimilar items). The need to control for semantic relatedness between items meant that those Nrp items that were similar to Rp + items appeared only in the Nrp related to Rp+ condition, whereas those Nrp items that were similar to $\mathrm{Rp}-$ items appeared only in the Nrp related to $\mathrm{Rp}-$ condition.

Semantic similarity. Items in the unpracticed category that were semantically similar to items from the practiced category were drawn from three implicit categories (i.e., jewelry, clothing, and furniture). Each implicit category within the unpracticed category contained two items that were yoked with semantically related items in the practiced category. Thus, there were two items each of jewelry, clothing, and furniture in the practiced category (e.g., wedding ring, cufflinks, trainers, leather jacket, bookcase, and desk) and two items each of jewelry, clothing, and furniture in the unpracticed category (e.g., necklace, earrings, sweater, jeans, table, and armchair).

The semantic relatedness of items within these implicit categories had been established in earlier pilot work (see Experiment 1 for details). Here, however, we also wished to construct the subsets of items in such a way that there was a high level of similarity between some, but not for others. Using the pilot data, we checked the relatedness of each set by comparing each item in each subset with each item in all the other subsets. For example, in order to establish the semantic similarity of items in the Nrp similar to Rp - subset to items in the Nrp-dissimilar subset, all possible pairings were computed, and a value was assigned to each according to the frequency of pairings made in the pilot study. Thus, if no participants in the pilot study had paired desk with rucksack, the pairing was given a value of 0 , whereas if 3 participants had paired desk with fountain pen, the pairing was assigned a value of .3. Once a value had been assigned to each possible pairing, the total value of all the possible pairings for the two subsets being compared was divided by the total number of actual pairings made for those items from the two subsets. This allowed us to produce a mean similarity rating for each subset comparison, where 0 indicated no perceived similarity and 1 indicated that they were very similar. Mean similarity for the following comparisons was calculated: $\mathrm{Rp}+$ vs. $\mathrm{Rp}-=.055 ; \mathrm{Rp}+$ vs. Nrp similar to $\mathrm{Rp}+=.713 ; \mathrm{Rp}+$ vs. Nrp similar to $\mathrm{Rp}-=.013 ; \mathrm{Rp}+$ vs. Nrp-dissimilar $=.012 ; \mathrm{Rp}-$ vs. Nrp similar to $\mathrm{Rp}+=.014$; $\mathrm{Rp}-$ vs. Nrp similar to $\mathrm{Rp}-=.713 ; \mathrm{Rp}-$ vs. Nrp-dissimilar $=$ .081 ; Nrp similar to Rp+ vs. Nrp-dissimilar $=.044$; and Nrp similar to $\mathrm{Rp}-$ vs. Nrp-dissimilar $=.04$.

This pilot work confirmed that there was a high degree of semantic relatedness between $\mathrm{Rp}+$ items and Nrp similar to Rp+ items and between Rp - items and Nrp similar to Rp - items. Similarly, it was confirmed that there was little similarity between Rp+ items and Nrp similar to Rp - items and between Rp - items and Nrp similar to Rp + items. Thus, on finding evidence of cross-category impairment, we could be confident that the observed effect was due to the similarity between Rp+ items and Nrp similar to Rp+ items and was not due to any similarity between Rp- items and Nrp similar to Rp+ items. Similarly, on finding evidence of second-order effects, we could be confident that any effect was due to the level of similarity between Rp - items and Nrp similar to Rp - items, rather than to any semantic relatedness between $\mathrm{Rp}+$ items and $\mathrm{Nrp}$ similar to Rp- items.

In order to minimize the possibility of item effects, each participant was presented with 24 items (i.e., 12 items appeared in the practiced category and 12 in the unpracticed category) from a pool of 28 possible items. Given the exploratory nature of this experiment, we wished to maximize the likelihood of our finding cross-category and second-order effects. We felt that this could be best accomplished by employing as wide a range of items as possible. Thus, the participants in the Nrp related to Rp+ condition received 8 Nrp-dissimilar items and $4 \mathrm{Nrp}$ similar to Rp + items in the unpracticed set, whereas the participants in the Nrp related to Rp- condition received $8 \mathrm{Nrp}-$ dissimilar items and 4 Nrp similar to Rp- items in the unpracticed set (see Figure 7 for further details). In each relevant practice condition, one third of the participants received jewelry and clothing as semantic categories, one third of the participants received jewelry and furniture, and the final third of the participants received clothing and furniture. Although this design has the disadvantage that items are not kept constant across conditions, the inclusion of the control condition provided the necessary between-subjects baseline against which all the Nrp subset performances could be compared.

Recall booklets. The present experiment also employed the cueindependent method (spread over an eight-page booklet). Three items were cued on each page by presenting the participants with a novel cue plus a two-letter stem unique to that item. The appropriateness of the cues employed in the cue-independent task at final recall had also been established in earlier pilot work (see Experiment 1). Items belonging to the same semantic subcategory (e.g., jewelry) never appeared on the same or a subsequent page, in order to prevent the participants from using previously recalled items to prompt the recall of other related items. In addition, recall never commenced with the cuing of previously practiced items, in order to minimize the risk of output interference. Output order was manipulated in a manner similar to that already described in Experiment 1, with weaker items (i.e., Rp -, Nrp-dissimilar, Nrp similar to Rp +, or Nrp similar to Rp- items) being cued earlier than stronger items (i.e., $\mathrm{Rp}+\mathrm{items})$. The participants were prompted by the experimenter at 10 -sec intervals to respond to each cue.

Procedure. With the exception of the number of target items presented at study and the number of $\mathrm{Rp}+$ items cued during retrieval practice, the procedure was identical to that in Experiment 1. Twelve stolen items were presented within each narrative. The participants in the retrieval practice conditions were cued to retrieve 6 $\mathrm{Rp}+$ items, $6 \mathrm{Rp}-$ items, and $12 \mathrm{Nrp}$ items (8 of which were either Nrp similar to Rp + or Nrp similar to Rp-). The participants in the control condition (i.e., no relevant retrieval practice) were cued to recall all the items about both houses that had been presented to them previously (i.e., 12 items from the Thompson's house and 12 items from the Williams's house). On completion of the final recall task, the participants were thanked, debriefed, and dismissed.

\section{Results and Discussion}

Retrieval practice success rates were $86 \%$ and $84 \%$ in the Nrp related to $\mathrm{Rp}+$ and Nrp related to $\mathrm{Rp}-$ conditions, respectively. Across the two experimental conditions, mean recall for the practiced items from the practiced category (i.e., Rp+ items) was .92, whereas mean recall performance for the baseline Nrp dissimilar items was .76. See Table 2 for a summary of item type recall performance. To determine whether this facilitation effect was significant, we performed a 2 (treatment condition: Nrp related to $\mathrm{Rp}+$ or Nrp related to $\mathrm{Rp}-$ ) $\times 2$ (item type: $\mathrm{Rp}+$ or Nrp-dissimilar) mixed ANOVA. The analysis revealed a significant main effect of item type $[F(1,58)=$ 


\begin{tabular}{|l|l|l|}
\hline \multicolumn{1}{|c|}{ Study Booklet 1 } & \multicolumn{1}{|c|}{ Study Booklet 2 } & \multicolumn{1}{c|}{ Study Booklet 3 } \\
\hline leather jacket & table & table \\
trainers & bookcase & bookcase \\
sweater & desk & desk \\
jeans & armchair & armchair \\
wedding ring & leather jacket \\
cufflinks & cufflinks ring & trainers \\
necklace & necklace & sweater \\
earrings & jeans \\
& & \\
+16 semantically & +16 semantically & +16 semantically \\
unrelated items & unrelated items & unrelated items \\
(i.e., Nrp-dissimilar items) & (i.e., Nrp-dissimilar items) & (i.e., Nrp-dissimilar items) \\
\hline
\end{tabular}

Figure 7. Randomization of semantic subcategories in Experiment 2. Semantically unrelated Nrp-dissimilar items were: painting, lamp, guitar, PlayStation, mobile phone, hockey stick, microwave, vase, clock, stereo, telescope, camera, fountain pen, hammer, rucksack, and perfume. Eight of these items form the remaining items from the unpracticed category, and eight items form the remaining items from the practiced category. Each participant in the Nrp related to $R p+$ condition received six $R p+$ items. Four of these items were drawn from the semantic subcategories detailed above (e.g., table, bookcase, desk, armchair), plus an additional two semantically unrelated items (e.g., lamp, vase). In the Nrp related to Rp- condition, none of the Rp+ items was drawn from the semantic subcategories, and so all six $R p+$ items were semantically unrelated items (e.g., painting, lamp, guitar, PlayStation, mobile phone, hockey stick). In contrast, four of the Rp- items were drawn from the semantic subcategories (e.g., table, bookcase, desk, armchair), and the two remaining Rp-items were semantically unrelated to all other items (e.g., microwave, vase).

34.38, $\left.M S_{\mathrm{e}}=0.73, p<.001\right]$. Cohen's $f$ was calculated as an unbiased measure of effect size (Cohen, 1988) and indicated the presence of a large effect (Cohen's $f=.40$ ). Neither an effect of treatment condition $[F(1,58)=0.85$, n.s.] nor an interaction between item type and treatment condition was evident $[F(1,58)=0.16$, n.s. $]$.

Consistent with predictions, recall performance for the unpracticed items from the practiced category (i.e., Rpitems) was found to be significantly lower than that for the Nrp-dissimilar baseline ( $M \mathrm{~s}=.58$ vs. .76, respectively). A 2 (treatment condition: Nrp related to Rp+ or Nrp related to $\mathrm{Rp}-$ ) $\times 2$ (item type: $\mathrm{Rp}-$ or Nrp-dissimilar) mixed ANOVA revealed a medium-sized main effect of item type $\left[F(1,58)=23.77, M S_{\mathrm{e}}=1.03, p<.001 ;\right.$ Cohen's $f=$ .30]. Again, there was neither an effect of treatment condition $[F(1,58)=1.38$, n.s. $]$ nor an interaction between item type and treatment condition $[F(1,58)=0.10$, n.s. $]$. Thus, significant retrieval-induced forgetting effects were present for both Nrp related to Rp+ and Nrp related to $\mathrm{Rp}-$ conditions, despite the use of novel retrieval cues at final test, thereby providing a further replication of our first experiment and support for Anderson and Spellman's (1995) inhibitory model of memory.

We then considered the evidence for cross-category and second-order impairment. We accomplished this by comparing recall performance for Nrp items that were related to items in the practiced category against Nrp-dissimilar items. Specifically, we found that fewer Nrp similar to $\mathrm{Rp}+$ items $(M=.65)$ were reported than Nrp-dissimilar items $(M=.78)$. A paired samples $t$ test confirmed that this cross-category impairment $(-.13)$ was statistically significant $[t(29)=-2.51, p<.05]$. We then examined

Table 2

Mean Recall Performance as a Function of Item Types in Experiment 2

\begin{tabular}{|c|c|c|c|c|c|c|c|c|c|c|c|}
\hline \multirow[b]{3}{*}{ Condition } & \multicolumn{10}{|c|}{ Item Type } & \multirow{3}{*}{$\begin{array}{l}\text { Retrieval-Induced Forgetting } \\
{[(\mathrm{Rp}-)-(\text { Nrp Dissimilar })]}\end{array}$} \\
\hline & \multicolumn{2}{|c|}{$\mathrm{Rp}+$} & \multicolumn{2}{|c|}{$\mathrm{Rp}-$} & \multicolumn{2}{|c|}{$\begin{array}{c}\text { Nrp } \\
\text { Similar to } \\
\text { Rp }+\end{array}$} & \multicolumn{2}{|c|}{$\begin{array}{l}\text { Nrp } \\
\text { Similar to } \\
\text { Rp- }\end{array}$} & \multicolumn{2}{|c|}{$\begin{array}{c}\text { Nrp } \\
\text { Dissimilar }\end{array}$} & \\
\hline & $M$ & $S D$ & $M$ & $S D$ & $M$ & $S D$ & $M$ & $S D$ & $M$ & $S D$ & \\
\hline Nrp related to $\mathrm{Rp}+$ & .93 & .10 & .60 & .22 & .65 & .20 & & & .78 & 18 & -.18 \\
\hline Nrp related to $\mathrm{Rp}-$ & .91 & .12 & .56 & .20 & - & & .60 & .22 & .74 & .18 & -.18 \\
\hline Mean & .92 & .11 & .58 & .21 & .65 & .20 & .60 & .22 & .76 & .18 & -.18 \\
\hline
\end{tabular}

Note- $\mathrm{Rp}+$, practiced items from the practiced category; $\mathrm{Rp}-$, unpracticed items from the practiced category; Nrp similar to $\mathrm{Rp}+$, unpracticed items from the unpracticed category that are semantically similar to practiced items from the practiced category; Nrp similar to $\mathrm{Rp}-$, unpracticed items from the unpracticed category that are semantically similar to unpracticed items from the practiced category; Nrp dissimilar, unpracticed items from the unpracticed category that are semantically dissimilar to items from the practiced category. Recall of items in the control condition $=.77(S D=.12)$. 
the evidence for second-order impairment by comparing mean recall performance for Nrp similar to $\mathrm{Rp}-$ items with that for Nrp-dissimilar items $[M \mathrm{~s}=.60$ vs. .74 , respectively; $t(29)=-2.51, p<.05]$. Although we could have expected the impairment to have been smaller for second-order effects than for cross-category effects, the magnitude of the impairment in the present experiment was virtually identical $(-.14)$.

The inclusion of a between-subjects baseline (i.e., the nonrelevant retrieval practice condition) also allowed us to determine whether these decrements were due to actual drops in performance or elevations in the Nrpdissimilar baseline. In order to examine this possibility, we conducted a one-way ANOVA in which the mean recall performance in the control condition $(M=.76)$ was compared with recall performance for Nrp-dissimilar items in both the Nrp related to $\mathrm{Rp}+$ condition $(M=.78)$ and the Nrp related to $\mathrm{Rp}-$ condition $(M=.74)$. No effect of item type was detected $[F(2,89)=0.45$, n.s.], thereby confirming that the observed decrements were not due to an increase in the Nrp-dissimilar baseline.

Since these cross-category and second-order effects were calculated by comparing two different subsets of items that were not counterbalanced (i.e., Nrp similar to $\mathrm{Rp}+/ \mathrm{Rp}-$ and Nrp-dissimilar items formed discrete sets), we need to be confident that the observed decrement in semantically related items from the unpracticed set was not due to these items being intrinsically less memorable. In order to eliminate this possibility, we compared recall performance for semantically related items from the unpracticed category in the relevant retrieval practice conditions (i.e., Nrp-similar items from the Nrp related to Rp+ and Nrp related to $\mathrm{Rp}-$ conditions) with recall performance for equivalent items in the control condition, in which no relevant retrieval practice had occurred. Such an analysis provides us with a measure of the intrinsic memorability of these semantically related Nrp items, as well as providing us with an additional indication of the level of forgetting produced by selective retrieval practice procedure. In these comparisons, exactly the same items are being compared between participants. First, we conducted a one-way ANOVA in which recall performance of Nrp similar to $\mathrm{Rp}+$ items in the retrieval practice condition $(M=.65)$ was compared with recall performance for Nrp-similar items in the control condition $(M=.76)$. A significant effect was detected $[F(1,88)=7.83, p<.001]$, suggesting that the cross-category impairment was due to a genuine decrease in recall performance for Nrp similar to $\mathrm{Rp}+$ items, rather than Nrp similar to Rp+ items being lower in intrinsic memorability. Similarly, we conducted a one-way ANOVA in which we compared recall performance for Nrp similar to Rp- items $(M=.60)$ with recall for Nrpsimilar items in the control condition $(M=.76)$. Again, a significant effect emerged $[F(1,88)=14.24, p<.001]$. Thus, we can be confident that the second-order effect we had observed was also due to a genuine impairment in recall performance for the $\mathrm{Nrp}$ similar to $\mathrm{Rp}-$ items.

It is important to note that in each case, the recall of Nrp similar to $\mathrm{Rp}+$ and Nrp similar to $\mathrm{Rp}-$ items was prompted by novel retrieval cues at final test. If the observed patterns of forgetting had been due to noninhibitory factors, we would have expected no obvious impairment (see Anderson \& Spellman, 1995). The fact that the observed impairments remained provides further support for the notion that inhibitory mechanisms are likely to underlie these effects. In recall performance, Nrp items that were semantically unassociated with items in the practiced category were the only item type to be unaffected by the retrieval practice of $\mathrm{Rp}+$ items. This pattern of effects is entirely consistent with Anderson's account of inhibitory processing; that is, performance decrements emerge only where there is unwanted competition at retrieval. Importantly, the present experiment also established that crosscategory impairment occurred where Nrp items were semantically associated with $\mathrm{Rp}+$ items. Thus, not only does the present experiment clarify any doubts that may have arisen about the nature of cross-category impairment in Anderson and Spellman's study, but also it indicates that these effects may be widespread.

\section{GENERAL DISCUSSION}

On the basis of Anderson and Spellman's (1995) criteria, the present experiments provide empirical support for the view that inhibitory processes are responsible for the kind of forgetting typically observed in the retrieval practice paradigm. Even when retrieval cues used at final test differed from those employed at both study and retrieval practice phases, retrieval-induced forgetting still emerged (i.e., $\mathrm{Rp}-<\mathrm{Nrp}$ ). Anderson and Spellman contended that noninhibitory theories of forgetting have difficulty predicting this kind of impairment and that the emergence of retrieval-induced forgetting, despite the use of novel cues at test, provides strong evidence that the memorial representation itself is suppressed. This suppression, in turn, renders the memorial representation unavailable to conscious inspection. In addition, our first experiment indicates that these effects are not limited to established category-exemplar pairings, as typically employed by Anderson and colleagues, but extend to new associations that are episodically defined. It is increasingly likely, therefore, that these decrements in memory performance may have relevance for our understanding of memory beyond the confines of the experimental laboratory (for further discussion, see E. L. Bjork et al., 2006; M. D. MacLeod, 2002).

Having established cue-independent forgetting and the likely involvement of inhibitory processing, we turned to consider the major tenets of the inhibitory model put forward by Anderson and colleagues. The underlying rationale for their inhibitory account is that it occurs as a means of resolving retrieval competition (i.e., competition emanating from related memories). Indeed, Anderson, E. L. Bjork, and R. A. Bjork (2000) have demonstrated that retrieval-induced forgetting fails to occur where $\mathrm{Rp}+$ items are strengthened without active retrieval (e.g., through reexposure). Since the pattern suppression model of inhibitory processing assumes that memorial represen- 
tations are composed of feature units (Anderson \& Spellman, 1995; Dagenbach \& Carr, 1994), it is possible that semantically similar representations may overlap with one another, resulting in the sharing of features. This, in turn, makes it possible that when an Nrp item shares some of the inhibited features of either an $\mathrm{Rp}+$ or an $\mathrm{Rp}-$ item, it will also become the focus of inhibitory processing. Thus, this pattern of forgetting should extend to items in nonpracticed categories that are semantically linked to items in practiced categories, because of the competition they create at retrieval.

In order to explore this possibility further, we conducted an experiment to establish whether cross-category and second-order impairments would occur where complex prose materials were employed. Our experiment provides one of the first independent replications outside Anderson's own lab that such effects are possible. In addition, we clarified the distinction between second-order and cross-category effects, detailed the experimental design necessary to demonstrate such effects, and provided unequivocal evidence that Nrp items can be inhibited because of their semantic association with either Rp+ or $\mathrm{Rp}$ - items (or more correctly, their sharing of common retrieval cues). In doing so, we have clarified any doubts that may have arisen regarding the replicability of these effects. We also demonstrated that items from the unpracticed category that were semantically dissimilar to items in the practiced category remained unaffected by the prior retrieval of practiced items. Recall performance for these items did not differ from that in the control condition, in which there was an absence of relevant retrieval practice. Thus, our data are consistent with Anderson's view that inhibitory mechanisms are likely to be activated as a means of dealing with unwanted competition from related memories at retrieval.

Although we have found nothing that is at odds with Anderson's account, we believe that there is an alternative interpretation of these effects that also warrants consideration. Specifically, we differ from Anderson's account in terms of the form of inhibitory control that underlies these effects. Rather than inhibitory control operating via the active inhibition or suppression of the memorial representation itself, inhibitory control may operate by limiting the spread of activation. But what do we mean by this? In the following, we will outline our rationale as to how such a form of inhibitory control could account for the range of effects reported in the present article and will consider how such a mechanism might be operationalized in computational terms on the basis of a competitive learning model devised by Oram and MacLeod (2001).

Anderson and Spellman's (1995) pattern suppression model is often characterized as being in opposition to other well-established models of memory that demonstrate facilitatory priming (Neely, 1976, 1977) or spreading activation (Freedman \& Loftus, 1971; Loftus, 1973). We believe, however, that it is possible to account for both facilitatory and inhibitory effects within a single model of memory. If we accept that retrieval practice typically facilitates the retrieval of related items in memory in much the same way as priming can facilitate such activities as word identification (e.g., Meyer \& Schvaneveldt, 1971), it would seem to us that the system must also possess some way of dampening down or limiting the activation of unwanted related items. If there were no such mechanism, it would be likely that the retrieval process would be constantly swamped by the activation of nontarget memories that, in turn, would compete for retrieval. Also, given the inherent flexibility of the categorization process and the fact that activation can spread bidirectionally between superordinate and subordinate memories - that is, category exemplars can activate category labels, in addition to category labels having the potential to activate category exemplars (Underwood, 1965) - and that activation can, under certain circumstances, continue to spread among subordinate and superordinate items not directly associated with target items (McNamara \& Altarriba, 1988), it would seem reasonable to suppose that memory must have some means of limiting the spread of activation.

Our rationale, therefore, is entirely consistent with the argument made by Anderson and colleagues (Anderson, 2003; Anderson et al., 1994; Anderson \& Spellman, 1995) for a mechanism that reduces interference from unwanted related items in memory. We believe, however, that it is possible to effect such a reduction in interference by limiting the extent of activation. Specifically, we would argue that rather than operating at the level of the exemplar, inhibition operates at the level of the category. In this way, inhibitory control can ensure that connections are strengthened between only a limited number of categories and their exemplars, thereby maximizing our potential to learn. If there was no such inhibition between categories, the benefits of learning would be greatly reduced, because of the infinite number of connections that could be made. By controlling which items are activated, unwanted competitors can be prevented from reaching threshold for retrieval and, therefore, are less likely to be a source of interference.

Oram and MacLeod's (2001) competitive network model predicts that where connections between a particular category and an exemplar are strengthened through selective retrieval practice, the connections between that category cue and any associated but unpracticed exemplars will be simultaneously weakened. In other words, connection strength will increase between the category cue and the practiced $\mathrm{Rp}+$ items but will decrease between the category cue and any unpracticed $\mathrm{Rp}-$ items. This strengthening of connections between a particular category cue and the practiced $\mathrm{Rp}+$ items will also result in a decrease in the connection strength between the Rpitems and any related category cues, because of partial activation of the Rp - items. This pattern of strengthening and weakening the connections between items and category cues will also occur for Rp+ items. In other words, the model predicts that there should be greater forgetting of $\mathrm{Rp}+$ items where novel cues are employed at test, if it were not for the fact that participants can also use episodically defined cues (i.e., cues that they have just practiced). Given that the $\mathrm{Rp}+$ items are much stronger following 
selected retrieval practice, it would seem reasonable to predict that the use of such an episodic cue will result in $\mathrm{Rp}+$ items being better recalled than either $\mathrm{Rp}-$ or Nrp items, irrespective of whether independent cues have been employed at test or not. Nrp items that are unrelated to items in the practiced set, in contrast, will remain at the connection strength established during the initial study phase of the retrieval practice paradigm. Since there is no partial activation of these items as a result of the retrieval practice manipulation, the connection strength between the Nrp items and any related category cues will remain unaffected. This pattern of connection strengths, therefore, can readily account for both first-order effects (i.e., retrieval-induced forgetting) and cue-independent forgetting (Oram \& MacLeod, 2006).

We can also use this model to explain cross-category and second-order effects. The retrieval cue used during selected retrieval practice will activate the memory node for the practiced set, which, in turn, will activate the connection between the memory node and the practiced $\mathrm{Rp}+$ items. This activation, in turn, will partially activate any Nrp items that are related to $\mathrm{Rp}+$ items. As a consequence of this partial activation, the connection strength between the memory node for the unpracticed set and such activated Nrp items will become weaker, relative to that between the memory node for the unpracticed set and Nrp items that are unrelated to the practiced set. This pattern of connection strengths accounts for cross-category effects. Second-order effects can similarly be explained by this model. During retrieval practice, although the connection strength between the memory node for the practiced set and those items that are practiced is greatly increased, there will also be some partial activation of the links between the memory node and any unpracticed item. Note that retrieval cues employed during retrieval practice activate the memory node for the practiced set, and not the exemplars directly. Thus, this partial activation of $\mathrm{Rp}-$ items will also partially activate any related items in the Nrp set. As in the case of cross-category effects, this partial activation results in a weakening of the link between the memory node for the unpracticed set, relative to the connection strength between that memory node and any items unrelated to the practiced set (Oram \& MacLeod, 2006).

The critical point in our interpretation is that it is not necessary to postulate an inhibitory mechanism at the level of the memorial representation in order to account for the effects reported in the present article. Rather, these patterns in recall performance can be accounted for by the relative strengths of connections in a competitive network model made between exemplars and categories cues following selected retrieval practice. Inhibition, however, can still be considered important, in the sense that it keeps categories separate and allows a winner-takes-all strategy to be implemented; that is, when one category is activated, it lessens the likelihood of other categories being similarly activated (see Földiák, 1991; Oram \& Földiák, 1996). This kind of inhibition is consistent with the observation that we have precise control in accessing the domain of information specified by a retrieval cue (Nelson, McEvoy, \&
Friedrich, 1982). Also, unlike Starns and Hicks (2004), Oram and MacLeod's (2001) model has the advantage that there is no need to postulate a separate inhibitory mechanism that is activated only during retrieval practice. Rather, Oram and MacLeod's (2001) model can account for such effects as a function of the way in which information is categorized and learning occurs. It is our hope that these ideas will serve to encourage future research that will consider the level at which inhibition operates and how the spread of activation may be limited.

In summary, the present article serves to illustrate that the relationship between forgetting and remembering is a complex one. Under some circumstances, at least, it would appear that inhibition can be brought to bear on unwanted competitors at retrieval. Under other conditions, however, guided retrieval practice can serve to facilitate the retrieval of related material. The present experiments, applying Anderson and Spellman's (1995) criteria, amply demonstrate first-order, second-order, and cross-category impairments in the retrieval practice paradigm. What remains to be resolved, however, is the level at which inhibition operates. Whereas Anderson and colleagues contend that the exemplar itself is inhibited, we have postulated that inhibitory control operates at the level of the category in such a way that it limits the spread of activation to related exemplars. Finally, if we are to understand fully how memory works, we need to consider how it functions in context. By this, we mean that there is a need to consider how memory allows us to function in a complex social world in which processing goals are in a constant state of flux. Under certain circumstances, it may prove advantageous to inhibit related memories, whereas under other conditions the facilitation of related memories may be required. Any explanation of memory retrieval that involves inhibitory control must have this kind of flexibility at its core.

\section{REFERENCES}

Allen, G. A., Mahler, W. A., \& Estes, W. K. (1969). Effects of recall tests on long-term retention of paired associates. Journal of Verbal Learning \& Verbal Behavior, 8, 463-470.

Anderson, M. C. (2003). Rethinking interference theory: Executive control and the mechanisms of forgetting. Journal of Memory \& Language, 49, 415-445.

Anderson, M. C., \& Bell, T. (2001). Forgetting our facts: The role of inhibitory processes in the loss of propositional knowledge. Journal of Experimental Psychology: General, 130, 544-570.

Anderson, M. C., BJork, E. L., \& BJork, R. A. (2000). Retrievalinduced forgetting: Evidence for a recall-specific mechanism. Psychonomic Bulletin \& Review, 7, 522-530.

Anderson, M. C., \& BJork, R. A. (1994). Mechanisms of inhibition in long-term memory: A new taxonomy. In D. Dagenbach \& T. H. Carr (Eds.), Inhibitory processes in attention, memory, and language (pp. 265-325). San Diego: Academic Press.

Anderson, M. C., BJork, R. A., \& BJork, E. L. (1994). Remembering can cause forgetting: Retrieval dynamics in long-term memory. Journal of Experimental Psychology: Learning, Memory, \& Cognition, 20, 1063-1087.

Anderson, M. C., Green, C., \& McCulloch, K. C. (2000). Similarity and inhibition in long-term memory: Evidence for a two-factor theory. Journal of Experimental Psychology: Learning, Memory, \& Cognition, 26, 1141-1159.

Anderson, M. C., \& McCulloch, K. C. (1999). Integration as a gen- 
eral boundary condition on retrieval-induced forgetting. Journal of Experimental Psychology: Learning, Memory, \& Cognition, 25, 608629.

Anderson, M. C., \& Neely, J. H. (1996). Interference and inhibition in memory retrieval. In E. L. Bjork \& R. A. Bjork (Eds.), Memory (pp. 237-313). San Diego: Academic Press.

Anderson, M. C., \& Spellman, B. A. (1995). On the status of inhibitory mechanisms in cognition: Memory retrieval as a model case. Psychological Review, 102, 68-100.

Basden, D. R., \& Basden, B. H. (1995). Part-list cueing: A retrieval strategy disruption interpretation. Journal of Experimental Psychology: Learning, Memory, \& Cognition, 21, 1656-1669.

Basden, D. R., Basden, B. H., \& Galloway, B. C. (1977). Inhibition with part-list cueing. Journal of Experimental Psychology: Human Learning \& Memory, 3, 100-108.

BJork, E. L., BJork, R. A., \& ANDERson, M. C. (1998). Varieties of goal-directed forgetting. In J. M. Golding \& C. M. MacLeod (Eds.), Intentional forgetting (pp. 103-137). Mahwah, NJ: Erlbaum.

BJoRK, E. L., BJork, R. A., \& MACLEOD, M. D. (2006). Types and consequences of forgetting: Intended and unintended. In L.-G. Nilsson \& N. Ohta (Eds.), Memory and society: Psychological perspectives (pp. 134-159). London: Psychology Press.

BJORK, R. A. (1989). Retrieval inhibition as an adaptive mechanism in human memory. In H. L. Roediger, III \& F. I. M. Craik (Eds.), Varieties of memory and consciousness: Essays in honor of Endel Tulving (pp. 309-330). Hillsdale, NJ: Erlbaum.

CARrier, M., \& PASHLER, H. (1992). The influence of retrieval on retention. Memory \& Cognition, 20, 633-642.

CoHen, J. (1988). Statistical power analysis for the behavioral sciences (2nd ed.). Hillsdale, NJ: Erlbaum.

DAGENBACH, D., \& CARR, T. H. (1994). Inhibitory processes in perceptual recognition: Evidence for a center-surround attentional mechanism. In D. Dagenbach \& T. H. Carr (Eds.), Inhibitory processes in attention, memory, and language (pp. 327-357). San Diego: Academic Press.

FöLDIÁK, P. (1991). Learning invariance from transformation sequences. Neural Computing, 3, 194-200.

Freedman, J. L., \& Loftus, E. F. (1971). Retrieval time from semantic memory. Journal of Verbal Learning \& Verbal Behavior, 10, $107-$ 115 .

Johnson, S. K., \& Anderson, M. C. (2004). The role of inhibitory control in forgetting semantic knowledge. Psychological Science, 15, 448-453.

LANDAUER, T. K., \& BJoRK, R. A. (1978). Optimum rehearsal patterns and name learning. In M. M. Gruneberg, P. E. Morris, \& R. N. Sykes (Eds.), Practical aspects of memory (pp. 625-632). London: Academic Press.

LeVY, B. J., \& Anderson, M. C. (2002). Inhibitory processes and the control of memory retrieval. Trends in Cognitive Sciences, 6, 299305 .

LofTUs, E. F. (1973). Category dominance, instance dominance, and categorization time. Journal of Experimental Psychology, 97, 70-74.

MacLeod, C. M., Dodd, M. D., Sheard, E. D., Wilson, D. E., \& BIвI, U. (2003). In opposition to inhibition. In B. H. Ross (Ed.), The psychology of learning and motivation (Vol. 43, 163-214). San Diego: Academic Press.

MacLeod, M. D. (2002). Retrieval-induced forgetting in eyewitness memory: Forgetting as a consequence of remembering. Applied Cognitive Psychology, 16, 135-149.

MacLeod, M. D., BJork, E. L., \& BJork, R. A. (2003). The role of retrieval-induced forgetting in the construction and distortion of memories. In B. Kokinov \& W. Hirst (Eds.), Constructive memory (NBU Series in Cognitive Science, pp. 55-68). Sophia: New Bulgarian University.

MacLeod, M. D., \& Macrae, C. N. (2001). Gone but not forgotten: The transient nature of retrieval-induced forgetting. Psychological Science, 12, 148-152.

Macrae, C. N., \& MacLeod, M. D. (1999). On recollections lost: When practice makes imperfect. Journal of Personality \& Social Psychology, 77, 163-173.

Macrae, C. N., \& Roseveare, T. A. (2002). I was always on my mind: The self and temporary forgetting. Psychonomic Bulletin \& Review, 9, 611-614.

McNamara, T. P., \& Altarriba, J. (1988). Depth of spreading activation revisited: Semantic mediated priming occurs in lexical decisions. Journal of Memory \& Language, 27, 545-559.

MeYer, D. E., \& SchVANEVELDT, R. W. (1971). Facilitation in recognizing pairs of words: Evidence of a dependence between retrieval operations. Journal of Experimental Psychology, 90, 227-234.

Neely, J. H. (1976). Semantic priming and retrieval from lexical memory: Evidence for facilitatory and inhibitory processes. Memory \& Cognition, 4, 648-654.

NeELy, J. H. (1977). Semantic priming and retrieval from lexical memory: Roles of inhibitionless spreading activation and limited capacity attention. Journal of Experimental Psychology: General, 106, 226-254.

Nelson, D. L., McEvoy, C. L., \& Friedrich, M. A. (1982). Extralist cuing and retrieval inhibition. Journal of Experimental Psychology: Learning, Memory, \& Cognition, 8, 89-105.

ORAM, M. W., \& FöLDIÁK, P. (1996). Learning generalisation and localisation: Competition for stimulus type and receptive field. Neurocomputing, 11, 297-321.

Oram, M. W., \& MacLeod, M. D. (2001). Remembering to forget: Modelling inhibitory and competitive mechanisms in human memory. In J. D. Moore \& K. Stenning (Eds.), Proceedings of the 23rd Annual Conference of the Cognitive Science Society (pp. 738-743). Mahwah, NJ: Erlbaum.

Oram, M. W., \& MacLeod, M. D. (2006). Modelling retrieval-induced forgetting: Where's the inhibition gone? Manuscript in preparation.

Roediger, H. L., III, \& McDermotT, K. B. (1995). Creating false memories: Remembering words not presented in lists. Journal of Experimental Psychology: Learning, Memory, \& Cognition, 21, 803-814.

Sahakyan, L., \& Kelley, C. M. (2002). A contextual change account of the directed forgetting effect. Journal of Experimental Psychology: Learning, Memory, \& Cognition, 28, 1064-1072.

Saunders, J., \& MacLeod, M. D. (2002). New evidence on the suggestibility of memory: The role of retrieval-induced forgetting in misinformation effects. Journal of Experimental Psychology: Applied, $\mathbf{8}, 127-142$.

SAUNDERS, J., \& MACLeOD, M. D. (2004, May). Inhibitory processes can influence the reporting of misleading post-event information. Poster presented at the 16th American Psychological Society Annual Convention, Chicago.

Shaw, J. S., III, BJoRK, R. A., \& Handal, A. (1995). Retrieval-induced forgetting in an eyewitness-memory paradigm. Psychonomic Bulletin \& Review, 2, 249-253.

Shivde, G., \& Anderson, M. C. (2001). The role of inhibition in meaning selection: Insights from retrieval-induced forgetting. In D. Gorfein (Ed.), On the consequences of meaning selection: Perspectives on resolving lexical ambiguity (pp. 175-190). Washington, DC: American Psychological Association.

Smith, R. E., \& Hunt, R. R. (2000). The influence of distinctive processing on retrieval-induced forgetting. Memory \& Cognition, 28, 503-508.

Snedecor, G. W., \& Cochran, W. G. (1980). Statistical methods (7th ed.). Ames: Iowa State University Press.

StaRns, J. J., \& Hicks, J. L. (2004). Episodic generation can cause semantic forgetting: Retrieval-induced forgetting of false memories. Memory \& Cognition, 32, 602-609.

UNDERWOOD, B. J. (1965). False recognition produced by implicit verbal responses. Journal of Experimental Psychology, 70, 122-129.

WATKINs, M. J. (1975). Inhibition in recall with extralist "cues." Journal of Verbal Learning \& Verbal Behavior, 14, 294-303.

WATKINS, M. J. (1978). Engrams and cuegrams and forgetting as cueoverload: A cueing approach to the structure of memory. In C. R. Puff (Ed.), The structure of memory (pp. 347-372). New York: Academic Press. 
APPENDIXA

Materials for Experiment 1

\section{Thompson's House}

Mr. and Mrs. Thompson and their twelve year old daughter Elizabeth live in the country. During the school holidays the Thompsons spent a week in Italy. On arriving back from their vacation, they discovered that their house had been broken into during their absence. Once the police arrived, the family was asked to take an inventory of all the missing items. Due to the dry weather that week tyre tracks were found in the dirt of the drive and the police believed that this indicated that the burglar or burglars had been driving a van. The police also believe that the burglar or burglars broke into the house through the patio doors.

Attached is a list of items that were stolen (the items are underlined).

The hockey stick had been stored in the cupboard in the hallway. It had belonged to the daughter who had been part of the school's team.

The mobile phone had been in the hallway. It had belonged to Mr. Thompson who needed it for his job as a doctor.

The PlayStation had been in the sitting room. It had been lying on the floor.

The armchair had been in the sitting room. It had been next to the patio doors.

The guitar had been in the daughter's room. She had been learning to play.

The painting had been in the dining room. It had been framed in the middle of the wall.

The microwave had been in the kitchen. It had been by the window.

The lamp had been in the kitchen. It had been in the corner of the room.

The necklace had been in the master bedroom. It had been in a red presentation box.

The vase had been in the sitting room. It had been on the window ledge.

\section{Williams's House}

Mr. and Mrs. Williams and their sixteen year old son, Jack, live in the suburbs of a city. On New Year's Day, Mr. and Mrs. Williams dropped their son off at a friend's house for the evening and then went to relatives. On arriving back at $10 \mathrm{pm}$ the Williams discovered that they had been burgled. Once the police arrived, the family were asked to take an inventory of all the missing items. After the police had examined the area, they believed that the burglars had gained access to the house by breaking the study window. Footprints in the snow also suggested that there were two burglars.

Attached is a list of items that were stolen (the items are underlined).

The perfume had been in the bathroom. It had belonged to Mrs. Williams and had been a Christmas gift.

The rucksack had been in the son's bedroom. It had been in his school bag but the police believe that the burglars had used it for carrying small items.

The hammer had been in the workshop. It had been lying on the floor.

The fountain pen had been in the study. Mrs. Williams is a teacher and used it to mark schoolwork.

The telescope had been in the conservatory. It had been set up so that it was pointing at the sky.

The leather jacket had been in the son's bedroom. It had been hanging from a clothes hook on the wall.

The clock had been in the bathroom. It had been hanging on the wall.

The printer had been in the study. It had been a Christmas present for the Williams's son.

The calculator had been in the study. The Williams use it for their accounts.

The stereo had been in the son's bedroom. It had been on a shelf.

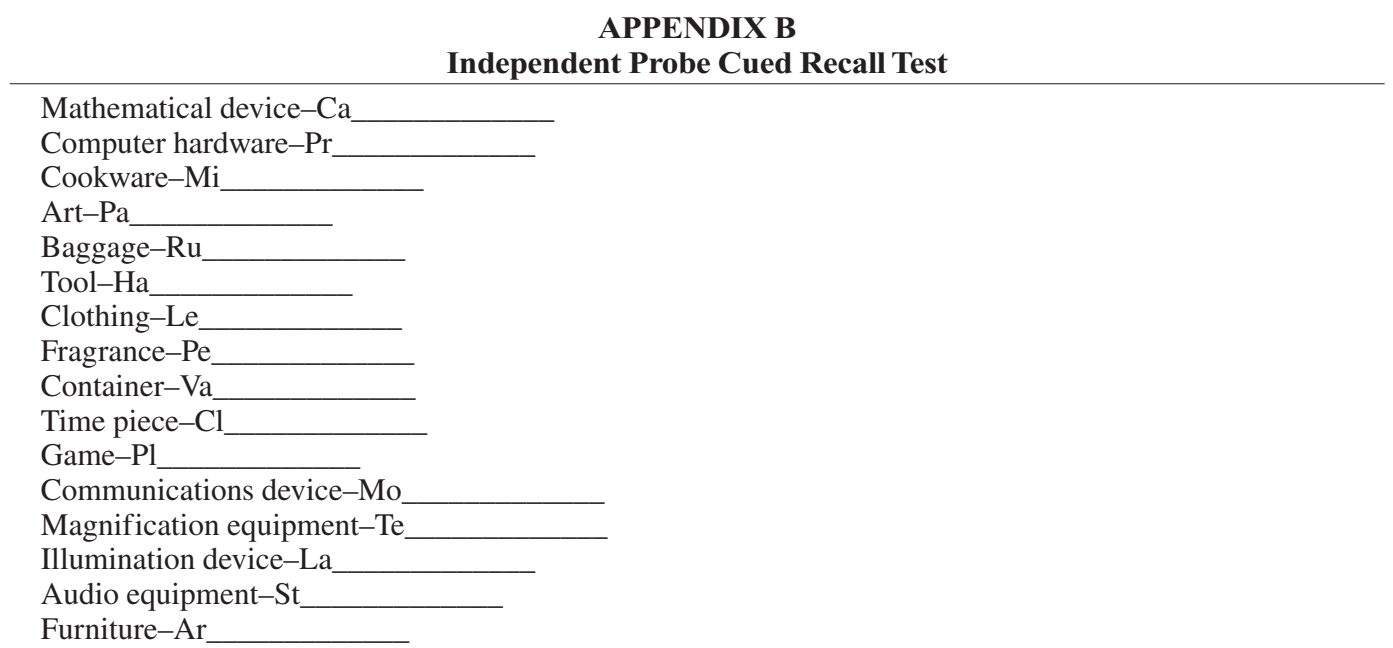


APPENDIX B (Continued)

Writing implement-Fo

Sports equipment-Ho

Musical instrument-Gu

Jewelry-Ne

\section{APPENDIX C \\ Materials for Experiment 2}

The scene-setting information contained within the narratives employed in Experiment 2 was the same as that used in Experiment 1. Only the target items differed.

\section{Thompson's House}

The hockey stick had been in the cupboard in the hallway. It had belonged to the daughter who had been part of the school's team.

The mobile phone had been in the hallway. It had belonged to Mr. Thompson who needed it for his job as a doctor.

The PlayStation had been in the sitting room. It had been lying on the floor.

The guitar had been in the daughter's room. She had been learning to play.

The painting had been in the dining room. It had been framed in the middle of the wall.

The microwave had been in the kitchen. It had been by the kitchen window.

The lamp had been in the kitchen. It had been in the corner of the room.

The vase had been in the sitting room. It had been on the window ledge.

The necklace had been in the master bedroom. It had been in a red presentation box.

The earrings had been in the daughter's room. They had been in a small jewelry box.

The table had been in the dining room. The Thompson family ate their breakfast at it every morning.

The armchair had been in the sitting room. It had been next to the patio doors.

The sweater had been in the master bedroom. It had been hung on a clothes hook on the back of the door.

The jeans had been in the daughter's room. They had been lying on the floor.

\section{Williams's House}

The stereo had been in the son's bedroom. It had been on a shelf.

The perfume had been in the bathroom. It had belonged to Mrs. Williams and had been a Christmas gift.

The rucksack had been in the son's bedroom. It had been his school bag but the police believe that the burglars had used it to carry small items in.

The hammer had been in the workshop. It had been lying on the floor.

The fountain pen had been in the study. Mrs. Williams is a teacher and used it to mark schoolwork.

The camera had been in the conservatory. It had been set up on a tripod.

The telescope had been in the conservatory. It had been set up so that it was pointing at the sky.

The clock had been in the bathroom. It had been hung on the wall.

The desk had been in the study. Mrs. Williams is a teacher and prepares her lessons at it.

The bookcase had been in the master bedroom. It had been by the door.

The trainers had been in the workshop. Mr. Williams had just bought them in the sales.

The leather jacket had been in the son's bedroom. It had been hung on a clothes hook on wall.

The wedding ring had been in the bathroom. Mrs. Williams has arthritis and had left it by the sink.

The cufflinks had been in the master bedroom. Mr. Williams wore them on formal occasions.

(Manuscript received August 12, 2004;

revision accepted for publication March 4, 2005.) 